\title{
Biological role of NK cells and immunotherapeutic approaches in breast cancer
}

\author{
María P. Roberti ${ }^{1}$, José Mordoh ${ }^{1,2}$ and Estrella M. Levy ${ }^{1 *}$ \\ ${ }^{1}$ Centro de Investigaciones Oncológicas, Fundación Cáncer FUCA, Buenos Aires, Argentina \\ 2 Fundación Instituto Leloir, IIBBA-CONICET, Buenos Aires, Argentina
}

\author{
Edited by: \\ Eric Vivier, Centre d'Immunologie de \\ Marseille-Luminy, France \\ Reviewed by: \\ Jacques Zimmer, Centre de \\ Recherche Public de la Santé, \\ Luxembourg \\ John T. Vaage, Oslo University \\ Hospital, Rikshospitalet and \\ University of Oslo, Norway \\ *Correspondence: \\ Estrella M. Levy, Centro de \\ Investigaciones Oncológicas, \\ Fundación Cáncer FUCA, Zabala \\ 2836, 1426 Buenos Aires, Argentina. \\ e-mail: estrellamlevy@yahoo.com.ar
}

In recent decades, tumor surveillance by the immune system and its impact on disease outcomes in cancer patients in general and in breast cancer (BC) patients in particular has been documented. Natural killer (NK) cells are central components of the innate immunity and existing data indicate that they play a role in preventing and controlling tumor growth and metastasis. Their biological significance was first recognized by their ability to exert direct cellular cytotoxicity without prior sensitization. This is important in tumors, as transforming events are likely to result in downregulation of self-ligands and expression of stress-induced ligands which can be recognized by NK cells. Their activation also leads to secretion of stimulatory cytokines which participate in cancer elimination by several direct mechanisms as well as by stimulating the adaptive immune system. In this regard, it was recently revealed a dendritic cell (DC)-NK-cell crosstalk which provides another novel pathway linking innate and adaptive immunity. In addition, NK cells are feasible targets of stimulation in immunotherapeutic approaches such as antibody-based strategies and adoptive cell transfer. Nevertheless, NK cells display impaired functionality and capability to infiltrate tumors in BC patients. This review compiles information about NK-cell biology in $\mathrm{BC}$ and the attempts which aim to manipulate them in novel therapeutic approaches in this pathology.

Keywords: natural killer (NK) cells, breast cancer, immunotherapy, immunosuppression, monoclonal antibodies

\section{INTRODUCTION}

Natural killer (NK) cells have been first described as innate effector lymphocytes and their biological significance has been first recognized by their ability to exert direct cellular cytotoxicity without prior sensitization (Herberman et al., 1975; Kiessling et al., 1975). The missing-self hypothesis established by Klas Kärre and collaborators postulates that NK cells recognize and eliminate their target cells by sensing the loss of self-major histocompatibility complex (MHC) class I molecules (Karre et al., 1986; Ljunggren and Karre, 1990). As counterpart, when MHC class I inhibition is absent, the NK-cell must still be stimulated through activation receptors. For instance, the upregulation of stress signals switched on in cells under stress triggers NK-cell activation (Bauer et al., 1999). Alternatively, FcyIII receptor CD16 binds the Fc portion of antibodies and trigger an antibody-dependent cellular cytotoxicity (ADCC) on opsonized target cells (Titus et al., 1987). The regulation of effector function of NK cells then depends on the integration of these positive and negative signals sensed on target cells. This is particularly important in tumors, as the events leading to transformation are likely to result in downregulation of self-ligands and expression of stress-induced ligands by tumor cells which can then be recognized by NK cells (Bottino et al., 2005; Garrido et al., 2010).

\section{IN VIVO EVIDENCE OF BC CONTROL BY NK CELLS IN A MOUSE MODEL}

Mouse models of human malignancies have contributed significantly to the understanding of disease pathogenesis as well as for preclinical therapeutic studies. Although several models mainly using conventional SCID mice are available, the major drawback is they still retain NK-cell, macrophage, complement, and dendritic cell (DC) activities. In contrast, NOD/SCID $/ \gamma^{\text {null }}$ (NSG) mice lack T, B, and NK cells which makes them a suitable model for tumor engraftment and to investigate the role of NK in tumor growth and metastasis (Ito et al., 2002). Using these models, the direct role of NK cells in tumor growth and metastasis was demonstrated in vivo by comparing NSG to conventional SCID mice. NSG mice inoculated with breast cancer (BC) cells were most efficient in the formation of large tumors within 2-3 weeks in all mice. Moreover, activated NK cells inhibited tumor formation and organ metastasis, suggesting that NK cells are responsible for inhibiting the formation of progressively growing rapid large tumors of BC cells in SCID mice (Dewan et al., 2007). A similar approach comparing wild type to NSG with BC cells showed that suppression of an Irf7-driven cluster of IFN-regulated genes is crucial to the establishment of bone metastases. Data showed that functional NK cells and $\mathrm{CD} 8^{+}$lymphocytes were both necessary for Irf7-induced and IFN-dependent 
immune activation to confer protection against metastasis but suggested that tumor immunosurveillance does not regulate the initiation of primary breast tumors. Furthermore, the clinical relevance of these findings was underscored in analyses of human primary tumors which revealed that high expression of the Irf7regulated genes in patients with $\mathrm{BC}$ was associated with less relapses to bone (Bidwell et al., 2012).

\section{BC BIOLOGY AND NK CELLS}

Human breast tumors can be categorized as luminal subtype A, luminal subtype B, HER-2 ${ }^{+}$, basal subtype, normal breastlike, and the recently introduced Claudin-low subtype, based on their molecular characteristics (Sorlie, 2004; Prat et al., 2010). However, differential gene expression patterns in breast tumor stroma led to the identification of subtypes corresponding to good and poor-outcome BCs independently of molecular tumor type. Interestingly, tumor stroma samples from the goodoutcome cluster overexpress a distinct set of immune-related genes, including T-cell and NK-cell markers indicative of a TH1type immune response (granzyme A, CD52, CD247, and CD8A) (Finak et al., 2008). Although there is no evidence to date for an association between NK-cell infiltrate and clinical outcome in patients with BC, the expression of NK-cell ligands does play a crucial role in tumor immunoediting and concomitant immune escape in BC. This evidence arose from studies of prognostic value of non-classical HLA class I molecule expression in BC patients which showed that in tumors devoid of classical HLA class I expression, HLA-E and HLA-G expression were of statistically significant influence on outcome of BC patients independently of known clinicopathological parameters, with an almost three-times higher risk of relapse over time for patients with expression of HLA-E/G compared with patients with no expression of HLA-E/G (De Kruijf et al., 2010). Furthermore, an analysis of the clinical prognostic value of the activating NK-cell receptor NKG2D ligands $\mathrm{MIC}-\mathrm{AB}$ and ULBP1-5 in early stage $\mathrm{BC}$ revealed that expression of $\mathrm{MIC}-\mathrm{AB}$ and ULBP-2 results in a favorable outcome concerning relapse-free survival (De Kruijf et al., 2012). Microarray data for NK-cell ligand expression in primary breast tumors showed that the different subtypes express heterogeneous levels of inhibitory HLA members, while some patterns of ligand expression represented the different molecular subtypes, which are characterized by distinct genomic alterations and deriving from different precursor cells, except for NKG2D and DNAM-1 ligands which are expressed in virtually all breast tumors regardless molecular subtype (Mamessier et al., 2011a).

Besides the described alterations in tumor molecules, there are several studies that have shown that peripheral blood NK cells from BC patients have impaired functionality as well (Garner et al., 1983; Dewan et al., 2009; Mamessier et al., 2011b), contributing to tumor escape from NK-cell control. Indeed, tumor infiltrating NK cells display a striking phenotype with downregulation of activating receptors and the upregulation of inhibitory receptors, and evidence suggests that the tumor induces its own tolerance from NK-cell antitumor immunity (Mamessier et al., $2011 \mathrm{a}, \mathrm{b})$. Altogether, the analysis of these data revealed that, on the one hand, genomic variability and associated tumorigenic features observed in BC resulted of some successful immunoedition and, on the other hand, the existence of mechanisms possibly used by breast tumor cells to immunosubvert NK cells. From this, current efforts are focusing in identifying potential targets which would contribute to enhance anti-tumor efficiency (Mamessier et al., 2012).

Aside from direct tumor immune evasion, NK cells are the target of multiple indirect tumor escape mechanisms such as generation and maintenance of T regulatory cells (Ghiringhelli et al., 2006), and myeloid derived suppressor cells (Condamine and Gabrilovich, 2011). The pathological relevance of this tolerogenic and immunosuppressant environment has lately been brought up in tumor models and in patients with BC (Wolf et al., 2003; Sceneay et al., 2012). Consequently, further assessment of the presence of these mechanisms in BC patients should be considered for a better understanding of the complexity of immunoevasion and for designing successful NK-cell-based immunotherapy of BC.

\section{NK CELLS IN BC THERAPEUTICS NK-CELL-BASED IMMUNOTHERAPIES}

Manipulating the immune system for therapeutic benefit in cancer patients has been studied for well over 100 years. Targeted treatments and immunotherapy are two of the most promising approaches to cancer, and each could be improved by basic research on NK cells. NK cells-based immunotherapy in BC patients has two main approaches. One of them proposes the direct administration of these cells stimulated ex vivo, whereas the second one involve the administration of drugs, mainly cytokines, to stimulate NK cells in the patients themselves. Although, there have been great efforts to stimulate NK cells in adoptive therapies, remaining challenges are related to the maintenance of NK-cell stimulation over time and to obtain improved clinical outcomes. The first clinical trials were developed in the early nineties and continue to the present. The most important clinical trials using NK-cell-based immunotherapy are listed in Table 1.

\section{THERAPEUTIC ANTIBODIES AND NK CELLS}

Targeting therapies with monoclonal antibodies (mAbs) are also important therapeutic strategies for cancer. The mAb trastuzumab has been approved for clinical use and has become a mainstay for HER2-positive BC (Slamon et al., 2001). Clinical efficacy is believed to rely mainly on the interference with the HER2 oncogenic signaling. In addition, one of the potential mechanisms of action of trastuzumab is NK-cell-mediated ADCC of the HER2-positve target cells. In this sense, the HER2 subtype is perhaps today the BC subtype in which we can explore the direct activity of NK cells in therapeutics. Trastuzumabmediated ADCC potency displayed by peripheral blood NK cells was shown to be correlated with the short-term response to treatment in metastatic BC patients (Beano et al., 2008). Further examination of factors affecting ADCC intensity and variability showed that the ability to develop ADCC in patients was significantly dependent on the quantity of $\mathrm{CD} 16^{+} \mathrm{CD} 56^{+}$lymphocytes among Peripheral blood Mononuclear Cell (PBMC). However, when quantity was normalized to target cell number, there was a relationship between CD16-158V/F polymorphism and the killing efficiency of $\mathrm{CD} 16^{+} \mathrm{CD} 56^{+}$cells (Varchetta 


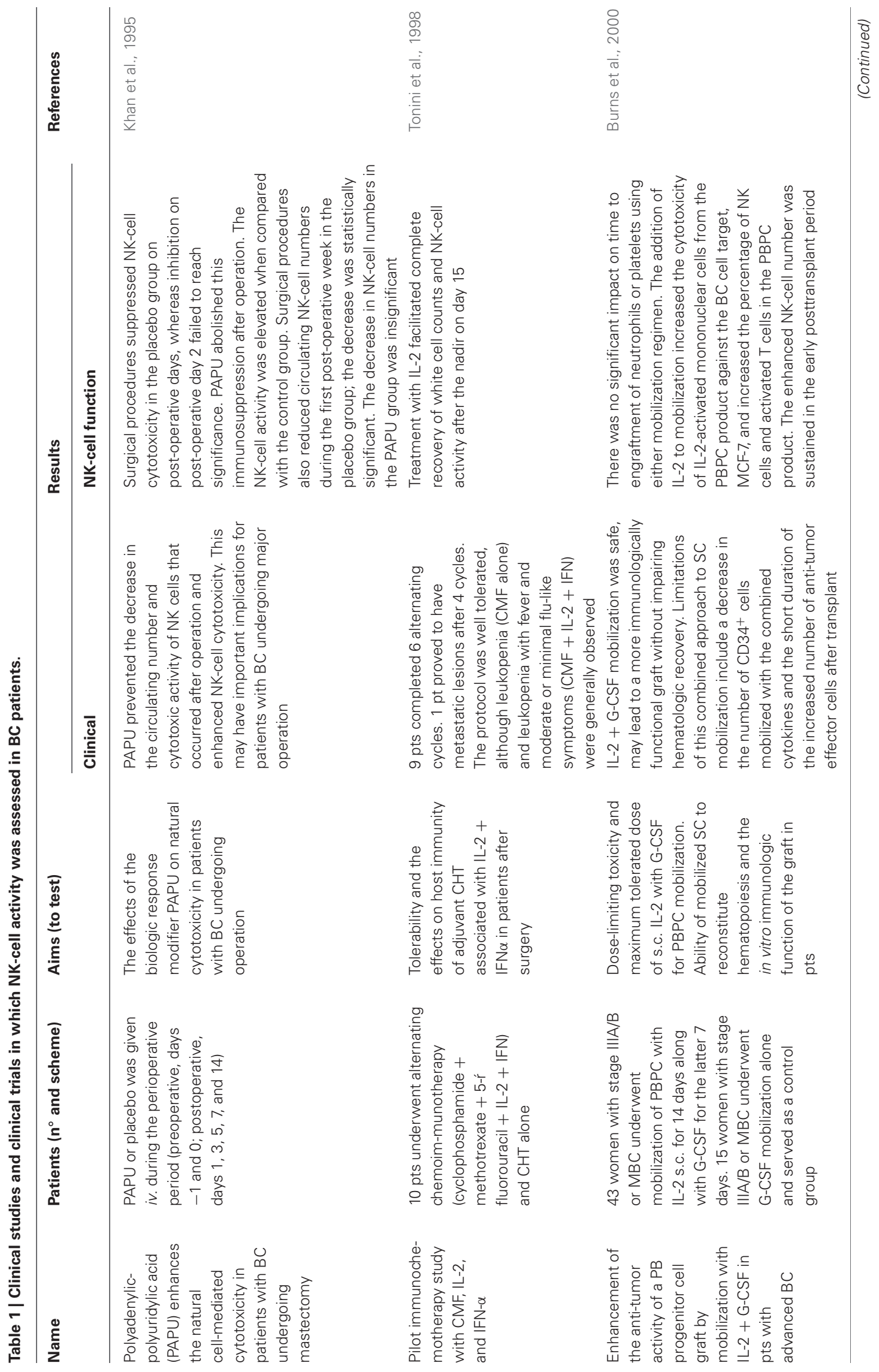




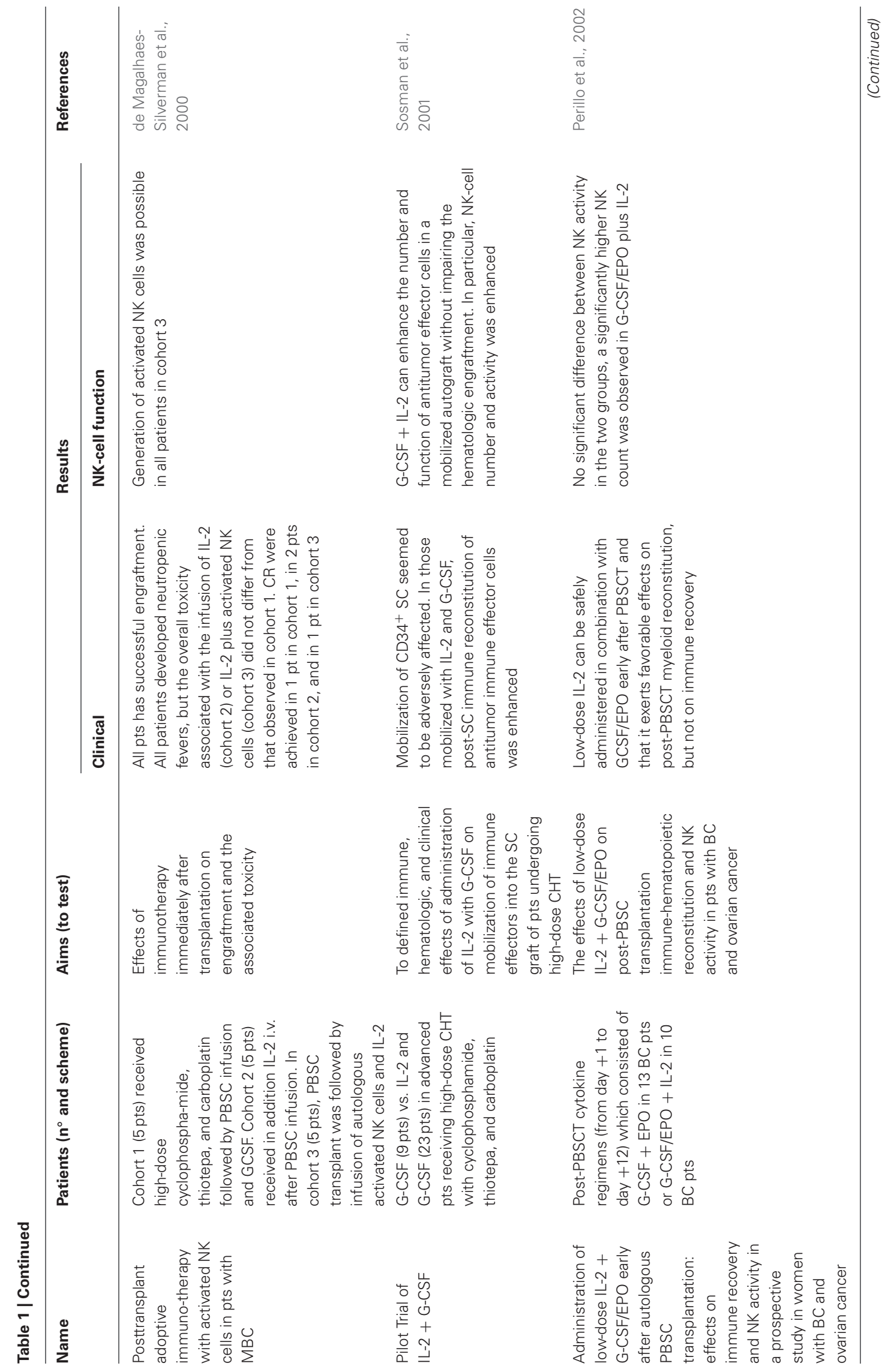




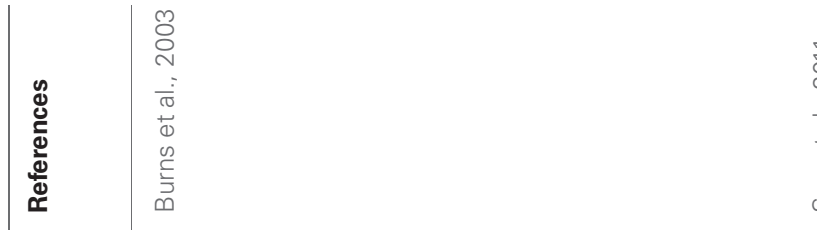

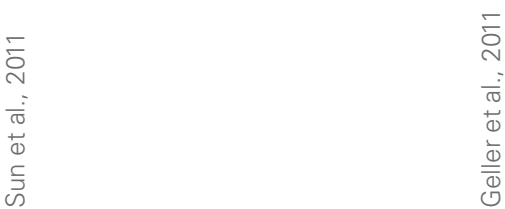

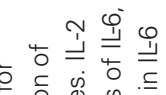

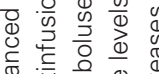

入

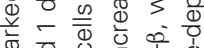

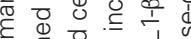

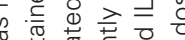

3 造, 这.

들 记

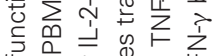

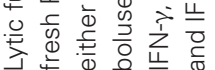

章

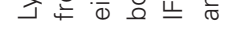

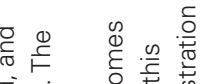

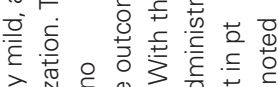

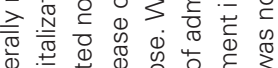

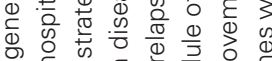

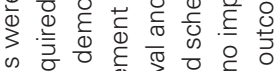

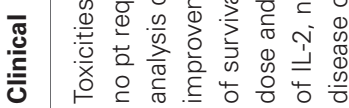

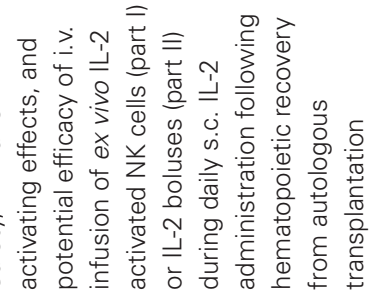

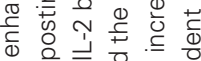

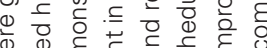

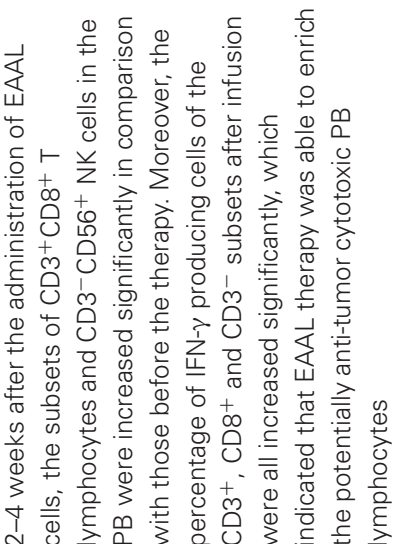

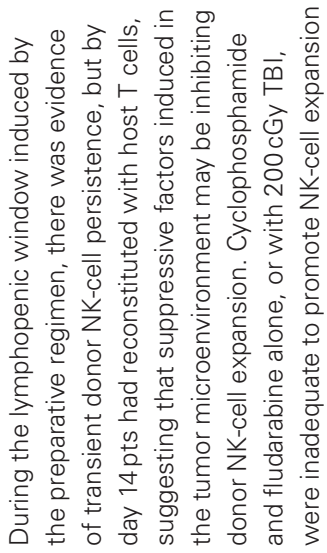

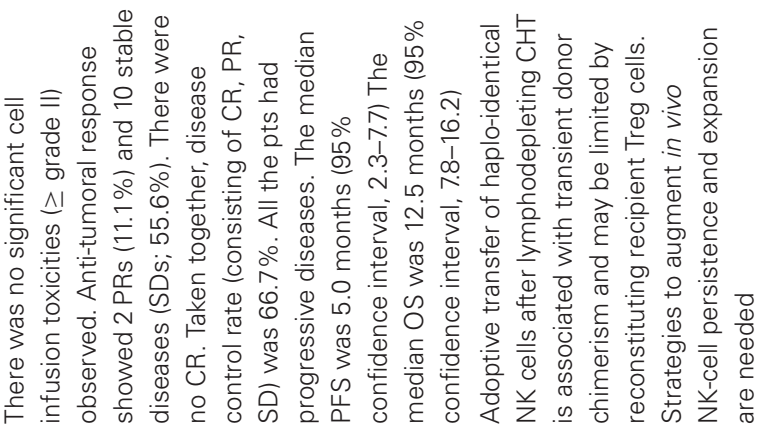

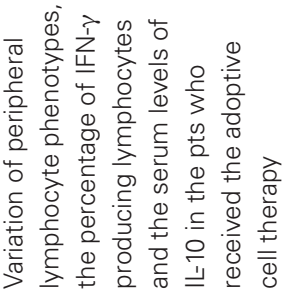

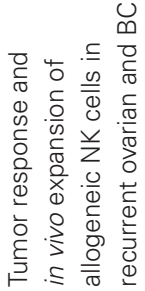

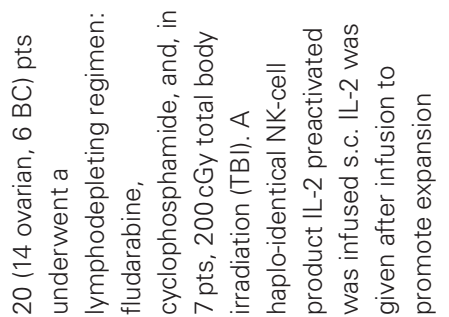

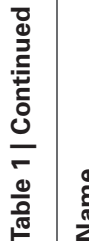

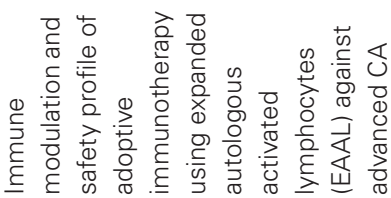

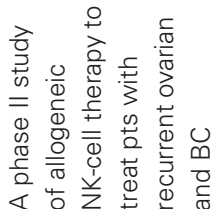




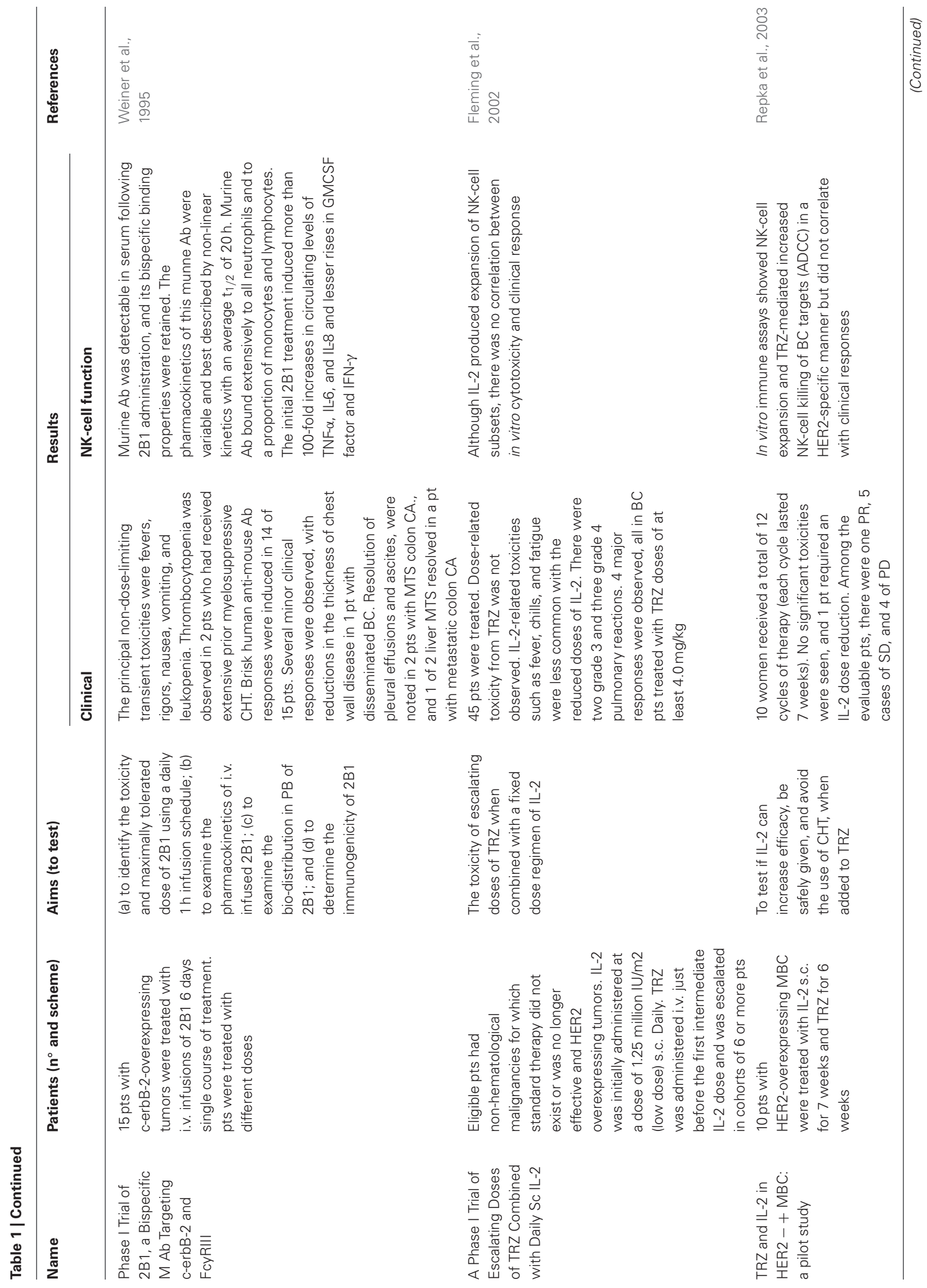




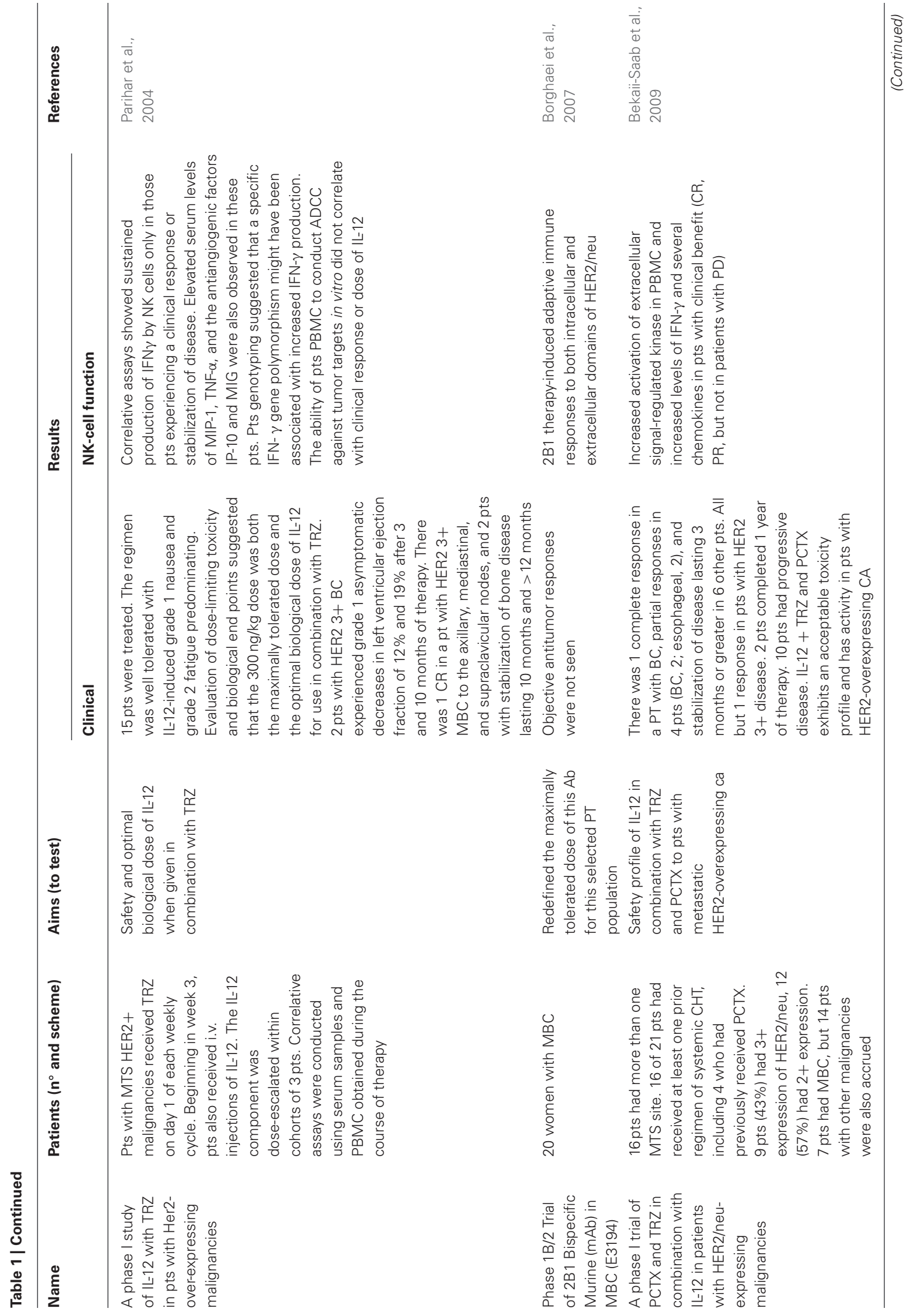




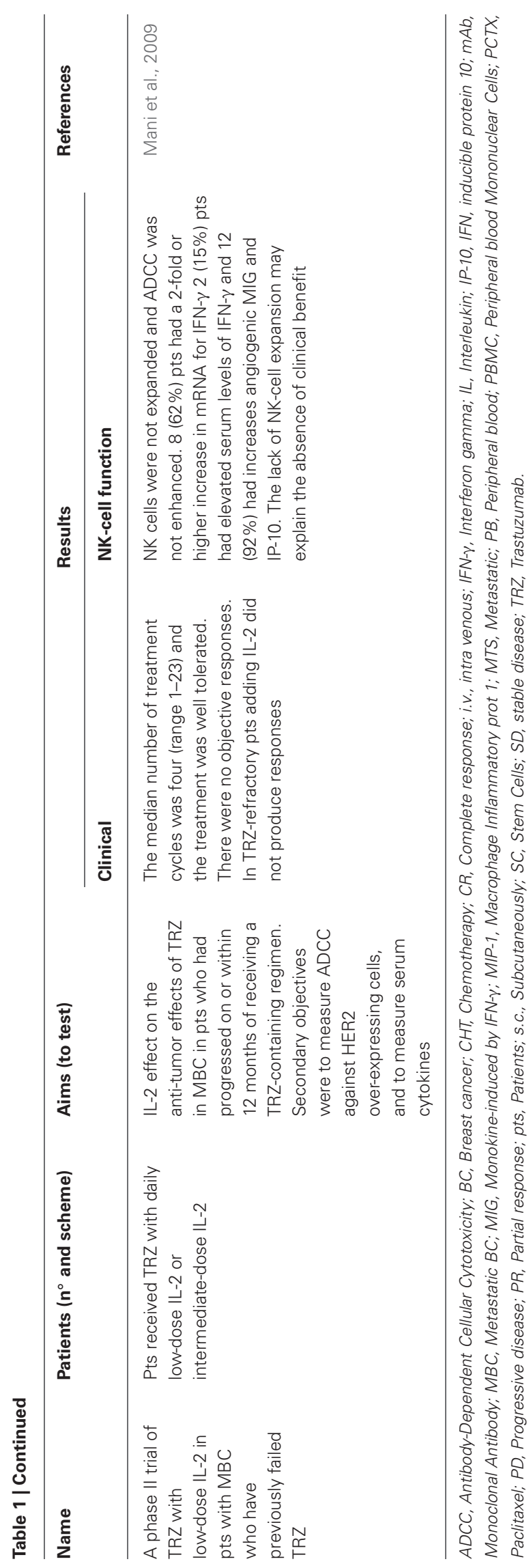

et al., 2007). However, the largest retrospective analysis to date evaluating an association between FCGR3A/2A genotypes and clinical outcome in trastuzumab-treated HER2-positive BC in the adjuvant setting showed no statistically significant correlation between FCGR3A and FCGR2A genotypes and disease-free survival in a cohort of 1286 patients treated with trastuzumabbased therapy in early BC nor in progression-free survival in 53 women treated with trastuzumab-based therapy for metastatic BC (Hurvitz et al., 2012). While these data do not entirely dismiss the possibility that trastuzumab triggers ADCC as one of its mechanisms of action, it does suggest that any differences in Fc-Fc $\gamma \mathrm{R}$ affinity attributed to the polymorphisms tested does not result in detectable differences in clinical outcome. In fact, other evidence supporting the ADCC role in trastuzumab therapeutic action was also demonstrated. E-cadherin-expressing HER2-overexpressing $B C$ cells were induced to treatment resistance toward trastuzumab, because ADCC activity was inhibited by interaction with E-cadherin and KLRG1 (Yamauchi et al., 2011). Recently, a novel N-terminal fragment of HER 2 was characterized (H2NTF) and found to be frequently expressed in breast tumor samples at variable levels. H2NTF is devoid of the tyrosine kinase domain but it readily interacts with fulllength HER2 and other HER receptors. Therefore, H2NTF acts as a dominant negative, attenuating the signaling triggered by full-length HER receptors. Expression of H2NTF results in resistance to the treatment with low concentrations of trastuzumab in vitro. However, cells expressing H2NTF and non-expressing cells have similar sensitivity to trastuzumab in vivo, indicating that H2NTF/trastuzumab complexes trigger ADCC (Morancho et al., 2012). Given the significance of the ADCC as antitumor function, it is reasonable to think that the efficiency of the host immune system could influence the responses to current therapy regimens. Recently, an immunophenotypic profiling of circulating and intratumor immune cells determined that compared to HER2-cases, patients with HER2-overexpressing locally advanced $\mathrm{BC}$ show a more limited tumor-related immune suppression (Muraro et al., 2011). This may account for the clinical benefit achieved in this subset of patients with the use of drugs acting through, but also promoting, immune-mediated effects.

Based on its ADCC mechanism, the anti-tumor efficacy of trastuzumab can be enhanced by means of combination with other immunomodulatory approaches such as chemotherapy, radiotherapy, targeted therapy agents, vaccines, or other immunomodulators. Table 1 also shows clinical trials that demonstrate the use and effectiveness of trastuzumab combined with different agents.

Experience with trastuzumab arouses the hope that mAbs could be used in other BC subtypes. Particularly important is the need for target therapies in basal $\mathrm{BC}$ as these patients are not likely to benefit from anti-estrogen or anti-HER2 therapy, and first-line treatment usually consists of conventional cytotoxic chemotherapy. Although basal BCs are quite sensitive to chemotherapeutic regimens in the preoperative setting, they are nevertheless associated with poor long-term outcomes (Liedtke et al., 2008). Nevertheless, better prognosis groups of basal BCs were identified on the basis of the expression of genes involved 
in antitumor immunity (Teschendorff et al., 2007; Sabatier et al., 2011a,b). As epidermal growth factor receptor (EGFR) is a targetable receptor frequently overexpressed in basal $\mathrm{BC}$, currently cetuximab, a mAb that binds EGFR, is being tested for efficacy in TNBC (Carey et al., 2012) and it was also shown in vitro that it triggers NK-cell-mediated ADCC (Roberti et al., 2011).

\section{NK-CELL-DC CROSSTALK}

Besides effector functions for tumor elimination and cytokine production, NK cells have mechanisms for stimulating the adaptive immune system, thus, being instrumental for enhancing antigen processing and presentation. Recent studies illustrate the potential of NK cells to increase the immunostimulatory capacity of DCs. It was demonstrated that NK cells can efficiently promote maturation and differentiation of DCs toward a Th1 profile (Mailliard et al., 2003). Hence, by inducing DC activation, NK-cell activation induced by tumor cells can indirectly promote antitumoral T-cell responses. Reciprocally, activated DCs induce potent NK-cell activation. Thus, NK-cell/DC crosstalk coordinates innate and adaptive immune responses influencing the quality and strength of the global immune response (Moretta et al., 2006). In line with this, it was recently identified that the interaction of cetuximab with EGFR on BC tumor cells and Fc $\gamma R$ IIIa on NK cells enhances cross-presentation of tumor antigens, such as EGFR, by DC to cytotoxic T lymphocytes (Lee et al., 2011). Regarding the evidence in clinical studies, correlation of

\section{REFERENCES}

Baek, S., Kim, C. S., Kim, S. B., Kim, Y. M., Kwon, S. W., Kim, Y., et al. (2011). Combination therapy of renal cell carcinoma or breast cancer patients with dendritic cell vaccine and IL-2: results from a phase I/II trial. J. Transl. Med. 9, 178.

Bauer, S., Groh, V., Wu, J., Steinle, A., Phillips, J. H., Lanier, L. L., et al. (1999). Activation of NK cells and $\mathrm{T}$ cells by NKG2D, a receptor for stress-inducible MICA. Science 285, 727-729.

Beano, A., Signorino, E., Evangelista, A., Brusa, D., Mistrangelo, M., Polimeni, M. A., et al. (2008). Correlation between NK function and response to trastuzumab in metastatic breast cancer patients. J. Transl. Med. 6, 25.

Bekaii-Saab, T. S., Roda, J. M., Guenterberg, K. D., Ramaswamy, B., Young, D. C., Ferketich, A. K., et al. (2009). A phase I trial of paclitaxel and trastuzumab in combination with interleukin-12 in patients with HER2/neu-expressing malignancies. Mol. Cancer Ther. 8, 2983-2991.

Bidwell, B. N., Slaney, C. Y., Withana, N. P., Forster, S., Cao, Y., Loi, S., et al. (2012). Silencing of Irf7 pathways in breast cancer cells promotes bone metastasis through immune escape. Nat. Med. doi: 10.1038/nm. 2830. [Epub ahead of print].

Borghaei, H., Alpaugh, R. K., Bernardo, P., Palazzo, I. E., Dutcher, J. P., Venkatraj, U., et al. (2007). Induction of adaptive AntiHER2/neu immune responses in a Phase $1 \mathrm{~B} / 2$ trial of $2 \mathrm{~B} 1$ bispecific murine monoclonal antibody in metastatic breast cancer (E3194): a trial coordinated by the Eastern Cooperative Oncology Group. J. Immunother. 30, 455-467.

Bottino, C., Castriconi, R., Moretta, L., and Moretta, A. (2005). Cellular ligands of activating NK receptors. Trends Immunol. 26, 221-226.

Burns, L. J., Weisdorf, D. J., Defor, T. E., Repka, T. L., Ogle, K. M., Hummer, C., et al. (2000). Enhancement of the anti-tumor activity of a peripheral blood progenitor cell graft by mobilization with interleukin 2 plus granulocyte colony-stimulating factor in patients with advanced breast cancer. Exp. Hematol. 28, 96-103.

Burns, L. J., Weisdorf, D. J., Defor, T. E., Vesole, D. H., Repka, T. L., Blazar, immunotherapy after autologous transplantation for lymphoma and breast cancer induces immune activation and cytokine release: a phase I/II trial. Bone Marrow Transplant. 32, 177-186. B. R., et al. (2003). IL-2-based

clinical responses in DC vaccine treated patients was reported. A phase I/II trial of an autologous DC vaccine combined with IL-2 induced specific immunity against introduced antigens and modifications of immunological parameters such as antigen-specific immune induction and NK-cell activation along with reduction of inhibitory immunity in vaccinated patients (Baek et al., 2011). However, the effect on the NK-cell population might be due to the IL-2 administration. In a more recent study of only autologous DC-based immunotherapy in treatment of stage II/IIIA BC patients data supports a correlation between positive immune responses induced by DC vaccination and improved long-term progress-free patient survival. DC vaccination was capable of promoting secretion of Th1 cytokines, as well as of significantly increased the number of peripheral blood NK cells and leding to tumor-specific $\mathrm{CD} 8^{+} \mathrm{T}$-cell expansion and further differentiation into IFN- $\gamma$-producing effector cells (Qi et al., 2012).

\section{PERSPECTIVES}

The compiling evidence of NK-cell biology in BC sheds light on the mechanisms involved in NK-cell tumor evasion and highlights the role of NK cells in the control of invasive breast tumors. However, regarding tumor strategies to overcome its elimination by innate immunity, it stresses the necessity of attempts which aim not only to stimulate NK cells directly but to target the tumor counterattack mechanisms in order to obtain clinical success in novel therapeutic approaches to battle this complex pathology.

Carey, L. A., Rugo, H. S., Marcom, P. K., Mayer, E. L., Esteva, F. J., Ma, C. X., et al. (2012). TBCRC 001: randomized phase II study of cetuximab in combination with carboplatin in stage IV triple-negative breast cancer. J. Clin. Oncol. 30, 2615-2623.

Condamine, T., and Gabrilovich, D. I. (2011). Molecular mechanisms regulating myeloid-derived suppressor cell differentiation and function. Trends Immunol. 32, 19-25.

De Kruijf, E. M., Sajet, A., Van Nes, J. G., Natanov, R., Putter, H., Smit, V. T., et al. (2010). HLA-E and HLA-G expression in classical HLA class I-negative tumors is of prognostic value for clinical outcome of early breast cancer patients. J. Immunol. 185, 7452-7459.

De Kruijf, E. M., Sajet, A., Van Nes, J. G., Putter, H., Smit, V. T., Eagle, R. A., et al. (2012). NKG2D ligand tumor expression and association with clinical outcome in early breast cancer patients: an observational study. BMC Cancer 12:24. doi: 10.1186/1471-2407-12-24

de Magalhaes-Silverman, M. Donnenberg, A., Lembersky, B., Elder, E., Lister, J., Rybka, W., et al. (2000). Posttransplant adoptive immunotherapy with activated natural killer cells in patients with metastatic breast cancer. J. Immunother. 23, 154-160.

Dewan, M. Z., Takada, M., Terunuma, H., Deng, X., Ahmed, S., Yamamoto, N., et al. (2009). Natural killer activity of peripheral-blood mononuclear cells in breast cancer patients. Biomed. Pharmacother. 63, 703-706.

Dewan, M. Z., Terunuma, H., Takada, M., Tanaka, Y., Abe, H., Sata, T., et al. (2007). Role of natural killer cells in hormone-independent rapid tumor formation and spontaneous metastasis of breast cancer cells in vivo. Breast Cancer Res. Treat. 104, 267-275.

Finak, G., Bertos, N., Pepin, F., Sadekova, S., Souleimanova, M., Zhao, H., et al. (2008). Stromal gene expression predicts clinical outcome in breast cancer. Nat. Med. 14, 518-527.

Fleming, G. F., Meropol, N. J., Rosner, G. L., Hollis, D. R., Carson, W. E. 3rd., Caligiuri, M., et al. (2002). A phase I trial of escalating doses of trastuzumab combined with daily subcutaneous interleukin 2: report of cancer and leukemia group B (9661). Clin. Cancer Res. 8, 3718-3727.

Garner, W. L., Minton, J. P., James, A. G., and Hoffmann, C. C. (1983). Human breast cancer and impaired NK cell function. J. Surg. Oncol. 24, 64-66. 
Garrido, F., Cabrera, T., and Aptsiauri, N. (2010). "Hard" and "soft" lesions underlying the HLA class I alterations in cancer cells: implications for immunotherapy. Int. J. Cancer $127,249-256$.

Geller, M. A., Cooley, S., Judson, P. L., Ghebre, R., Carson, L. F., Argenta, P. A., et al. (2011). A phase II study of allogeneic natural killer cell therapy to treat patients with recurrent ovarian and breast cancer. Cytotherapy 13, 98-107.

Ghiringhelli, F., Menard, C., Martin, F., and Zitvogel, L. (2006). The role of regulatory $\mathrm{T}$ cells in the control of natural killer cells: relevance during tumor progression. Immunol. Rev. 214, 229-238.

Herberman, R. B., Nunn, M. E., and Lavrin, D. H. (1975). Natural cytotoxic reactivity of mouse lymphoid cells against syngeneic acid allogeneic tumors. I. Distribution of reactivity and specificity. Int. J. Cancer 16, 216-229.

Hurvitz, S. A., Betting, D. J., Stern, H. M., Quinaux, E., Stinson, J., Seshagiri, S., et al. (2012). Analysis of Fcgamma receptor IIIa and IIa polymorphisms: lack of correlation with outcome in trastuzumab-treated breast cancer patients. Clin. Cancer Res. 18, 3478-3486.

Ito, M., Hiramatsu, H., Kobayashi, K., Suzue, K., Kawahata, M., Hioki, K., et al. (2002). NOD/SCID/gamma(c)(null) mouse: an excellent recipient mouse model for engraftment of human cells. Blood 100, 3175-3182.

Karre, K., Ljunggren, H. G., Piontek, G., and Kiessling, R. (1986). Selective rejection of $\mathrm{H}$-2-deficient lymphoma variants suggests alternative immune defence strategy. Nature 319, 675-678.

Khan, A. L., Richardson, S., Drew, J., Larsen, F., Campbell, M., Heys, S. D., et al. (1995). Polyadenylicpolyuridylic acid enhances the natural cell-mediated cytotoxicity in patients with breast cancer undergoing mastectomy. Surgery 118, 531-538.

Kiessling, R., Klein, E., and Wigzell, H. (1975). "Natural" killer cells in the mouse. I. Cytotoxic cells with specificity for mouse Moloney leukemia cells. Specificity and distribution according to genotype. Eur. J. Immunol. 5, 112-117.

Lee, S. C., Srivastava, R. M., LopezAlbaitero, A., Ferrone, S., and Ferris, R. L. (2011). Natural killer (NK): dendritic cell (DC) cross talk induced by therapeutic monoclonal antibody triggers tumor antigen-specific $\mathrm{T}$ cell immunity. Immunol. Res. 50, 248-254.

Liedtke, C., Mazouni, C., Hess, K. R., Andre, F., Tordai, A., Mejia, J. A., et al. (2008). Response to neoadjuvant therapy and long-term survival in patients with triple-negative breast cancer. J. Clin. Oncol. 26, 1275-1281.

Ljunggren, H. G., and Karre, K. (1990). In search of the 'missing self': MHC molecules and NK cell recognition. Immunol. Today 11, 237-244.

Mailliard, R. B., Son, Y. I., Redlinger, R., Coates, P. T., Giermasz, A., Morel, P. A., et al. (2003). Dendritic cells mediate NK cell help for Th1 and CTL responses: two-signal requirement for the induction of NK cell helper function. J. Immunol. 171, 2366-2373.

Mamessier, E., Bertucci, F., Sabatier, R., Birnbaum, D., and Olive, D. (2012). "Stealth" tumors: breast cancer cells shun NK-cells anti-tumor immunity. Oncoimmunology 1, 366-368.

Mamessier, E., Sylvain, A., Bertucci, F., Castellano, R., Finetti, P., Houvenaeghel, G., et al. (2011a). Human breast tumor cells induce self-tolerance mechanisms to avoid NKG2D-mediated and DNAMmediated NK cell recognition. Cancer Res. 71, 6621-6632.

Mamessier, E., Sylvain, A., Thibult, M. L., Houvenaeghel, G., Jacquemier, J., Castellano, R., et al. (2011b). Human breast cancer cells enhance self tolerance by promoting evasion from NK cell antitumor immunity. J. Clin. Invest. 121, 3609-3622.

Mani, A., Roda, J., Young, D., Caligiuri, M. A., Fleming, G. F., Kaufman, P., et al. (2009). A phase II trial of trastuzumab in combination with low-dose interleukin-2 (IL-2) in patients (PTS) with metastatic breast cancer (MBC) who have previously failed trastuzumab. Breast Cancer Res. Treat. 117, 83-89. Morancho, B., Parra-Palau, J. L., Ibrahim, Y. H., Bernado Morales, C., Peg, V., Bech-Serra, J. J., et al. (2012). A dominant-negative N-terminal fragment of HER2 frequently expressed in breast cancers. Oncogene. doi: 10.1038/onc.2012. 152. [Epub ahead of print].

Moretta, L., Ferlazzo, G., Bottino, C., Vitale, M., Pende, D., Mingari, M. C., et al. (2006). Effector and regulatory events during natural killer-dendritic cell interactions. Immunol. Rev. 214, 219-228.

Muraro, E., Martorelli, D., Turchet, E., Miolo, G., Scalone, S., Comaro, E., et al. (2011). A different immunologic profile characterizes patients with HER-2-overexpressing and HER-2-negative locally advanced breast cancer: implications for immune-based therapies. Breast Cancer Res. 13, R117.

Parihar, R., Nadella, P., Lewis, A., Jensen, R., De Hoff, C., Dierksheide, J. E., et al. (2004). A phase I study of interleukin 12 with trastuzumab in patients with human epidermal growth factor receptor-2-overexpressing malignancies: analysis of sustained interferon gamma production in a subset of patients. Clin. Cancer Res. 10, 5027-5037.

Perillo, A., Pierelli, L., Battaglia, A., Salerno, M. G., Rutella, S., Cortesi, E., et al. (2002). Administration of low-dose interleukin-2 plus GCSF/EPO early after autologous PBSC transplantation: effects on immune recovery and NK activity in a prospective study in women with breast and ovarian cancer. Bone Marrow Transplant. 30, 571-578.

Prat, A., Parker, J. S., Karginova, O., Fan, C., Livasy, C., Herschkowitz, J. I., et al. (2010). Phenotypic and molecular characterization of the claudin-low intrinsic subtype of breast cancer. Breast Cancer Res. 12, R68.

Qi, C. J., Ning, Y. L., Han, Y. S., Min, H. Y., Ye, H., Zhu, Y. L., et al. (2012). Autologous dendritic cell vaccine for estrogen receptor (ER)/progestin receptor (PR) double-negative breast cancer. Cancer Immunol. Immunother. 61, 1415-1424.

Repka, T., Chiorean, E. G., Gay, J., Herwig, K. E., Kohl, V. K., Yee, D., et al. (2003). Trastuzumab and interleukin-2 in HER2positive metastatic breast cancer: a pilot study. Clin. Cancer Res. 9, 2440-2446.

Roberti, M. P., Barrio, M. M., Bravo, A. I., Rocca, Y. S., Arriaga, J. M., Bianchini, M., et al. (2011). IL-15 and IL-2 increase Cetuximabmediated cellular cytotoxicity against triple negative breast cancer cell lines expressing EGFR. Breast Cancer Res. Treat. 130, 465-475.

Sabatier, R., Finetti, P., Cervera, N., Lambaudie, E., Esterni, B., Mamessier, E., et al. (2011a). A gene expression signature identifies two prognostic subgroups of basal breast cancer. Breast Cancer Res. Treat. 126, 407-420.

Sabatier, R., Finetti, P., Mamessier, E., Raynaud, S., Cervera, N., Lambaudie, E., et al. (2011b). Kinome expression profiling and prognosis of basal breast cancers. Mol. Cancer 10, 86.
Sceneay, J., Chow, M. T., Chen, A., Halse, H. M., Wong, C. S., Andrews, D. M., et al. (2012). Primary tumor hypoxia recruits CD11b+/Ly6Cmed/Ly6G+ immune suppressor cells and compromises NK cell cytotoxicity in the premetastatic niche. Cancer Res. 72 , 3906-3911.

Slamon, D. J., Leyland-Jones, B., Shak, S., Fuchs, H., Paton, V., Bajamonde, A., et al. (2001). Use of chemotherapy plus a monoclonal antibody against HER2 for metastatic breast cancer that overexpresses HER2. N. Engl. J. Med. 344, 783-792.

Sorlie, T. (2004). Molecular portraits of breast cancer: tumour subtypes as distinct disease entities. Eur. J. Cancer 40, 2667-2675.

Sosman, J. A., Stiff, P., Moss, S. M., Sorokin, P., Martone, B., Bayer, R., et al. (2001). Pilot trial of interleukin-2 with granulocyte colony-stimulating factor for the mobilization of progenitor cells in advanced breast cancer patients undergoing high-dose chemotherapy: expansion of immune effectors within the stem-cell graft and poststem-cell infusion. J. Clin. Oncol. 19, 634-644.

Sun, Z., Shi, L., Zhang, H., Shao, Y., Wang, Y., Lin, Y., et al. (2011). Immune modulation and safety profile of adoptive immunotherapy using expanded autologous activated lymphocytes against advanced cancer. Clin. Immunol. 138, 23-32.

Teschendorff, A. E., Miremadi, A. Pinder, S. E., Ellis, I. O., and Caldas, C. (2007). An immune response gene expression module identifies a good prognosis subtype in estrogen receptor negative breast cancer. Genome Biol. 8, R157.

Titus, J. A., Perez, P., Kaubisch, A. Garrido, M. A., and Segal, D. M. (1987). Human K/natural killer cells targeted with hetero-cross-linked antibodies specifically lyse tumor cells in vitro and prevent tumor growth in vivo. J. Immunol. 139, 3153-3158.

Tonini, G., Nunziata, C., Prete, S. P., Pepponi, R., Turriziani, M., Masci, G., et al. (1998). Adjuvant treatment of breast cancer: a pilot immunochemotherapy study with CMF, interleukin-2 and interferon alpha. Cancer Immunol. Immunother. 47, 157-166.

Varchetta, S., Gibelli, N., Oliviero, B., Nardini, E., Gennari, R., Gatti, G., et al. (2007). Elements related to heterogeneity of antibodydependent cell cytotoxicity in 
patients under trastuzumab therapy for primary operable breast cancer overexpressing Her2. Cancer Res. 67, 11991-11999.

Weiner, L. M., Clark, J. I., Davey, M., Li, W. S., Garcia De Palazzo, I., Ring, D. B., et al. (1995). Phase I trial of $2 \mathrm{~B} 1$, a bispecific monoclonal antibody targeting c-erbB-2 and Fc gamma RIII. Cancer Res. 55, 4586-4593.

Wolf, A. M., Wolf, D., Steurer, M., Gastl, G., Gunsilius, E., and Grubeck-Loebenstein, B. (2003).
Increase of regulatory $\mathrm{T}$ cells in the peripheral blood of cancer patients. Clin. Cancer Res. 9, 606-612.

Yamauchi, C., Fujii, S., Kimura, T., Kuwata, T., Wada, N., Mukai, H., et al. (2011). E-cadherin expression on human carcinoma cell affects trastuzumab-mediated antibody-dependent cellular cytotoxicity through killer cell lectin-like receptor G1 on natural killer cells. Int. J. Cancer 128, 2125-2137.
Conflict of Interest Statement: The authors declare that the research was conducted in the absence of any commercial or financial relationships that could be construed as a potential conflict of interest.

Received: 27 September 2012; paper pending published: 19 October 2012; accepted: 23 November 2012; published online: 12 December 2012.

Citation: Roberti MP, Mordoh J and Levy EM (2012) Biological role of NK cells and immunotherapeutic approaches in breast cancer. Front. Immun. 3:375. doi: 10.3389/fimmu.2012.00375

This article was submitted to Frontiers in NK Cell Biology, a specialty of Frontiers in Immunology.

Copyright (๑) 2012 Roberti, Mordoh and Levy. This is an open-access article distributed under the terms of the Creative Commons Attribution License, which permits use, distribution and reproduction in other forums, provided the original authors and source are credited and subject to any copyright notices concerning any third-party graphics etc. 